\title{
Efficacy and safety of long-course tacrolimus treatment for idiopathic membranous nephropathy
}

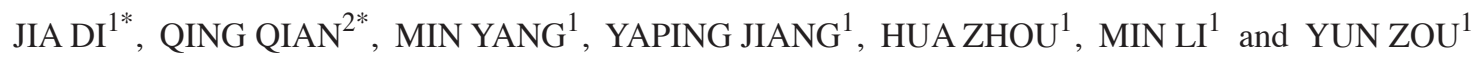 \\ Departments of ${ }^{1}$ Nephrology and ${ }^{2}$ Pharmacy, The First People's Hospital of Changzhou, \\ Changzhou, Jiangsu 213003, P.R. China
}

Received November 4, 2017; Accepted March 9, 2018

DOI: $10.3892 /$ etm.2018.6211

\begin{abstract}
The aim of the present study was to observe the efficacy and safety of long-course treatment with tacrolimus combined with low-dose corticosteroids for idiopathic membranous nephropathy (IMN). A total of 76 patients with IMN diagnosed by renal biopsy between March 2012 and January 2016 form The First People's Hospital of Changzhou (Changzhou, China) were selected and randomly divided into a short-course group and a long-course group (each, $n=38$ ). Patients in the short-course group were treated with hormone combined with tacrolimus for 12 months, whereas those in the long-course group received the same treatment for 24 months. The efficacy, safety and recurrence of the two groups of patients were observed, and serum ALB, urine protein, Scr and blood glucose were assessed once a month for 24 months by measuring blood biochemistry. A total of 11 patients exhibited adverse effects, 6 of whom were serious and as such were excluded from the study. In the short-course group, 8 of 35 patients demonstrated complete remission (CR), 17 patients exhibited partial remission (PR) and the remaining 10 patients had no remission (NR); however the disease recurred in 8 patients following treatment. In the long-course group, 16 of 35 patients exhibited CR, 14 patients demonstrated PR and the remaining 5 patients had NR. Furthermore, the disease recurred in 4 patients following treatment. Significant differences were observed in urine protein and serum ALB at 18 and 24 months following treatment between the two groups while Scr and blood glucose had no significant differences at any time point. It was concluded that long-course tacrolimus combined with low-dose hormone effectively treats idiopathic membranous nephropathy and that therapy demonstrated a relatively high remission rate, and the recurrence rate of the disease is low.
\end{abstract}

Correspondence to: Dr Yun Zou, Department of Nephrology, The First People's Hospital of Changzhou, 185 Juqian Street, Changzhou, Jiangsu 213003, P.R. China

E-mail: szouyun@163.com

${ }^{*}$ Contributed equally

Key words: nephrotic syndrome, idiopathic membranous nephropathy, tacrolimus

\section{Introduction}

Idiopathic membranous nephropathy (IMN) is a common cause of adult nephrotic syndrome and one of the leading causes of primary nephrotic syndrome (1). Although spontaneous remissions occur, IMN is an important cause of chronic kidney failure. It is pathologically associated with immune complex deposition under glomerular epithelial cells, thus leading to diffuse thickening of capillary basement membranes (2). The majority of patients (50-90\%) exhibit nephrotic syndromes, whereas others exhibit non-nephrotic proteinuria with a low incidence rate of hematuria (1). As the course of the disease is delayed, the drug treatment duration is long and its sensitivity to treatments varies $(1,3)$.

It is widely accepted that simple corticosteroid therapy is ineffective for the treatment of IMN $(3,4)$ and at present, corticosteroids therapy in combination with immunosuppressive agents is commonly utilized $(5,6)$. KDIGO Clinical Practice Guidelines for Glomerulonephritis recommends Calcineurin inhibitors, either cyclosporine or tacrolimus as the major therapeutic option in patients with primary membranous nephropathy (4). Tacrolimus is a novel immunosuppressive agent, which effectively inhibits the activation and proliferation of $\mathrm{T}$ cells and has been widely used in anti-rejection and autoimmune diseases following renal transplantation (5-7). In recent years, tacrolimus has been utilized more frequently for the treatment of IMN and has achieved notable results, but the recurrence rate of IMN is clinically high following drug withdrawal (8-10). At present, the duration of tacrolimus treatment remains inconclusive. The present study assessed the efficacy and safety of different courses of tacrolimus administration in, combination with low-dose prednisolone for the treatment of IMN.

\section{Patients and methods}

Participants. A total of 76 patients with IMN who were hospitalized at the First People's Hospital of Changzhou (Changzhou, China) between March 2012 and January 2016 were included in the present study. These patients, including 43 males and 33 females, were aged from 17-78 years old with a mean age of $47.4 \pm 17.1$ years. The inclusion criteria were as follows: i) Patients pathologically diagnosed with IMN at stage I-III based on the KDIGO Clinical Practice Guidelines (1); ii) patients with serum creatinine $(\mathrm{Scr})<221 \mu \mathrm{mol} / \mathrm{l}$; and 
iii) pregnancy-bearing female patients with negative pregnancy test results, who agreed to take contraceptive measures. Exclusion criteria were as follows: i) Patients with infections, malignant tumors, tuberculosis or other serious kidney diseases; ii) patients who were administered corticosteroids or other immunosuppressive agents within the last month; iii) patients with abnormal liver function, or type 1 or 2 diabetes mellitus; and iv) patients allergic to macrolide drugs. Patients were randomly divided into the short-course and long-course groups (each, n=38). Patients in the short-course group were treated with prednisone $(0.5 \mathrm{mg} / \mathrm{kg} /$ day $)$ combined with tacrolimus (0.1 mg/kg/day) (both Yangze Pharma Company, Taizhou, China) for 12 months, whereas those in the long-course group were treated with the same combination for 24 months. The present study was approved by the Ethics Committee of the First People's Hospital of Changzhou. Written, informed consent was obtained from all participants prior to enrollment. Due to severe adverse effects 6 of the patients were excluded and a total of 70 patients finished the study.

Different therapies. Patients in both groups were administered low-dose prednisone $(0.5 \mathrm{mg} / \mathrm{kg} / \mathrm{day})$ combined with tacrolimus $(0.1 \mathrm{mg} / \mathrm{kg} / \mathrm{day})$ orally for routine treatment. At 8 weeks following initial administration, the dose of prednisone was reduced by $5 \mathrm{mg}$ every 4 weeks and then maintained at a total of $10 \mathrm{mg}$ per day. The short-course treatment group received tacrolimus $(0.1 \mathrm{mg} / \mathrm{kg} /$ day $)$ once every $12 \mathrm{~h}$; patients were administered the drug orally when fasting ( $0.5 \mathrm{~h}$ prior to meals). Following 1 week of treatment, the plasma concentration of tacrolimus was monitored using a Microparticle Enzyme Immunoassay kit (cat. no. AH875420; Abbott Laboratories, Abbott Park, IL, USA) according to the manufacturer's protocol. In the first month, the concentration was detected once a week and following this, was assessed once per month. If the concentration was $<5 \mu \mathrm{g} / \mathrm{l}$, the dosage of tacrolimus was increased until the plasma concentration was maintained at $5-10 \mu \mathrm{g} / \mathrm{l}$. This cut off value was based on a previous study (1). At 6 months of treatment, the plasma concentration of tacrolimus was maintained at 2-4 $\mu \mathrm{g} / \mathrm{l}$ and patients continued treatment until the 12 month period ended. The long-course group were administered the same treatment as the short-course group. At 6 months following treatment, plasma concentration of tacrolimus plasma concentration was maintained at $2-4 \mu \mathrm{g} / 1$ and patients continued to receive this dosage until the 24 month treatment period had ended.

Observation indicators. Patients were followed-up once a week in the first month following tacrolimus treatment and were subsequently followed-up once a month for 24 months. Mild, moderate and high degree edema refers to edema below the ankle joint, below the knee joint and above the knee joint, respectively as previously described (1). Hemoglobin was measured using a whole blood analyzer (Hitachi, Ltd., Tokyo, Japan) in accordance with the manufacturers' protocol. Albumin (ALB), Scr, 24 h urinary protein quantification and blood glucose were measured using the automatic biochemical analyzer (Hitachi, Ltd.). Changes in tacrolimus concentration were monitored and adverse effects for the duration of treatment, including severe infection, elevated blood sugar and renal dysfunction were recorded.
Evaluation of therapeutic efficiency. Clinical efficacy was divided into complete remission (CR), partial remission (PR) and no remission (NR). CR was achieved when urinary protein was $<0.3 \mathrm{~g}$ and normal serum ALB levels and renal function was exhibited. PR was determined when urinary protein was 0.3-3.0 g, or when its basal value was reduced by $>50 \%$. In addition serum albumin had to be $\geq 30 \mathrm{~g} / 1$ with stable renal function. NR was considered when the efficacy did not reach the criteria for PR. Recurrence was determined after the efficacy reached CR or PR, but symptoms in line with the diagnostic criteria for nephrotic syndromes recurred in the course of administration. Repeated occurrence occurred when the efficacy reached PR, but various incentives led to elevated levels of urinary protein, which did not meet the diagnostic criteria for nephrotic syndromes.

Statistical analysis. SPSS 17.0 statistical software (SPSS, Inc., Chicago, IL, USA) was used for analyses. Normal distributed quantitative data were expressed as the mean \pm standard deviation and quantitative data was expressed as frequency. The rank-sum test was utilized for rank data. One way analysis of variance followed by the least significant difference post-hoc test was conducted for repeated measures data using a general linear model with intergroup comparisons and comparisons at different time points. Student's t-test was used for intergroup comparisons of measurement data. $\mathrm{P}<0.05$ was considered to indicate a statistically significant difference.

\section{Results}

Baseline characteristics of patients in the two groups. A total of 70 patients completed the treatment protocol. The baseline characteristics of the short- and long-course groups are presented in Table I. The mean age was $47.9 \pm 17.1$ years in the short-course group and $46.9 \pm 15.4$ years in the long-course group, and the male/female ratio was $22 / 13$ and 20/15 in the short- and long-course groups, respectively. The course of disease was $11.6 \pm 5.3$ months in the short-course group and $12.5 \pm 5.0$ months in the long-course group. In the short-course group, 26 patients exhibited moderate to high-degree edema and 30 patients exhibited massive proteinuria and hypoproteinemia. In the long-course group, 25 patients presented moderate to high-degree edema and a total 31 patients exhibited massive proteinuria and hypoproteinemia (including the 30 patients in the short course group). There were no statistically significant differences in sex, age, course of disease prior to treatment and stage of the disease between the two groups.

Comparison of the efficacy between two groups of patients. At the end of treatment, the short-course group included 8 cases of CR, 17 cases of PR and 10 cases of NR (Table II). The long-course group exhibited 16 cases of CR, 14 cases of PR and 5 cases of NR. There was a significant difference in the ratio of CR to NR in the long-course group compared with the short-course group $(\mathrm{P}<0.05$; Table II). The disease recurrence rate was significantly increased in the short-course group (8 cases) compared with the long-course group (4 cases; $\mathrm{P}<0.05$; Table II).

Comparison of proteinuria and biochemical indices at different treatment time points between the two patient groups. 
Table I. Baseline characteristics of patients in the short- and long-course groups.

\begin{tabular}{lcr}
\hline Groups & $\begin{array}{c}\text { Short-course } \\
\text { treatment group }\end{array}$ & $\begin{array}{c}\text { Long-course } \\
\text { treatment group }\end{array}$ \\
\hline Age, years (mean \pm SD) & $47.9 \pm 17.1$ & $46.9 \pm 15.4$ \\
Sex (male/female) & $22 / 13$ & $20 / 15$ \\
Course of disease prior to treatment, months (mean \pm SD) & $11.6 \pm 5.3$ & $12.5 \pm 5.0$ \\
Moderate to high-degree edema & 26 & 25 \\
Massive proteinuria & 30 & 31 \\
Hypoproteinemia & 30 & 31 \\
IMN at Stage I & 5 & 7 \\
IMN at Stage II & 25 & 22 \\
IMN at Stage III & 5 & 6 \\
\hline
\end{tabular}

Data are presented as n, unless otherwise stated. SD, standard deviation; IMN, idiopathic membranous nephropathy.

Table II. Comparison of efficacy between the short- and long-course treatment groups.

\begin{tabular}{|c|c|c|c|c|c|}
\hline Group & $\mathrm{CR}(\%)$ & PR (\%) & NR $(\%)$ & $\mathrm{RR}(\%)$ & P-value \\
\hline Short-course treatment group & $8(22.8)$ & $17(48.6)$ & $10(28.6)$ & $8(22.8)$ & 0.011 \\
\hline IMN at stage I & $2(5.7)$ & $2(5.7)$ & $1(2.9)$ & $2(5.7)$ & \\
\hline IMN at stage II & $6(17.1)$ & $13(37.1)$ & $6(17.1)$ & $3(8.6)$ & \\
\hline IMN at stage III & $0(0.0)$ & $2(5.7)$ & $3(8.6)$ & $3(8.6)$ & \\
\hline Long-course treatment group & $16(45.7)^{\mathrm{a}}$ & $14(40.0)$ & $5(14.3)^{\mathrm{a}}$ & $4(11.4)$ & \\
\hline IMN at stage I & $3(8.6)$ & $3(8.6)$ & $1(2.9)$ & $1(2.9)$ & \\
\hline IMN at stage II & $12(34.3)$ & $8(22.8)$ & $2(5.7)$ & $2(5.7)$ & \\
\hline IMN at stage III & $1(2.9)$ & $3(8.6)$ & $2(5.7)$ & $1(2.9)$ & \\
\hline
\end{tabular}

${ }^{a} \mathrm{P}<0.05$ vs. short-course treatment group. IMN, idiopathic membranous nephropathy; $\mathrm{CR}$, complete remission; PR, partial remission; NR, no remission; $\mathrm{RR}$, recurrence rate.

In the short-course group, at 1 month following treatment, the quantity of urine proteins was significantly decreased compared with the levels prior to treatment in 16 patients $(\mathrm{P}<0.01$; Table III); at 6 months following treatment, 6 patients had completely recovered to normal; at 12 months following treatment, 8 patients had completely recovered to normal; following drug withdrawal, the disease recurred in 8 patients. At 1 month following treatment, serum ALB levels in 28 patients were significantly increased compared with levels prior to treatment $(\mathrm{P}<0.01)$, which was subsequently ameliorated in 10 , 13 and 17 patients at 3,6 and 12 months following treatment, respectively. In the long-course group, at 1 month following treatment, the quantity of urine proteins in 15 patients was significantly decreased compared with levels prior to treatment $(\mathrm{P}<0.01)$, which was subsequently ameliorated in 5, 9, 13 and 16 patients at $6,12,18$ and 24 months following treatment, respectively. At 24 months following treatment, the disease recurred in 4 patients. At 1 month following treatment, the serum ALB level in patients 27 was significantly elevated, which was subsequently ameliorated in 9,15 and 18 patients at 3, 6 and 12 months following treatment, respectively. Statistically significant differences in the quantity of urine protein and serum ALB were observed at 18 and 24 months following treatment in the long-course group compared with the short-course group $(\mathrm{P}<0.05$; Tables III and IV). However, no significant differences in the mean levels of Scr and blood glucose at any time point prior to and following treatment between the two groups were observed (Tables V and VI).

Adverse effects. A total of 11 patients exhibited adverse effects, 6 of whom were excluded due to severe adverse effects at 2-10 months following the initiation of treatment. Among patients with severe adverse effects, 4 suffered severe pneumonia, of whom 3 succumbed following invalid rescue, 1 suffered lung abscess and 1 suffered interstitial lung disease. The remaining 5 patients exhibited elevated blood glucose, 2 in the short-course treatment group and 3 in the long-course group. Following diet control or drug treatment, the blood glucose levels returned to normal. The incidence rate of adverse effects was $13.1 \%$ in the short-course group and $15.8 \%$ in the long-course group; this difference was not statistically significant. However, the mortality rate $(3.9 \%)$ of patients with severe adverse events, particularly those with severe pneumonia, was high, which should trigger clinical application vigilance. Patients were divided into two groups according to whether adverse effects occurred. Univariate analyses were conducted for age, sex, 
Table III. Comparison of urine protein content prior to and following treatment between the short- and long-course groups.

\begin{tabular}{|c|c|c|c|c|}
\hline \multirow[b]{2}{*}{ Time point } & \multicolumn{2}{|c|}{ Urine protein content (g/day) } & \multicolumn{2}{|c|}{ Urine protein recovered to normal (\%) } \\
\hline & $\begin{array}{l}\text { Short-course } \\
\text { treatment group }\end{array}$ & $\begin{array}{l}\text { Long-course } \\
\text { treatment group }\end{array}$ & $\begin{array}{l}\text { Short-course } \\
\text { treatment group }\end{array}$ & $\begin{array}{l}\text { Long course } \\
\text { treatment group }\end{array}$ \\
\hline Prior to treatment & $10.4 \pm 5.9$ & $10.2 \pm 6.3$ & - & - \\
\hline \multicolumn{5}{|c|}{ Following treatment } \\
\hline 1 month & $5.8 \pm 4.4^{\mathrm{a}}$ & $6.0 \pm 5.3^{\mathrm{a}}$ & $3(8.6)$ & $3(8.6)$ \\
\hline 3 months & $3.7 \pm 3.3$ & $4.2 \pm 2.5$ & $5(14.3)$ & $4(11.4)$ \\
\hline 6 months & $2.5 \pm 0.6$ & $2.3 \pm 0.7$ & $6(17.1)$ & $5(14.3)$ \\
\hline 12 months & $2.0 \pm 0.4$ & $1.9 \pm 0.5$ & $8(22.8)$ & $9(25.7)$ \\
\hline 18 months & $2.5 \pm 0.7$ & $0.8 \pm 0.3^{\mathrm{b}}$ & $9(25.7)$ & $13(37.1)^{b}$ \\
\hline 24 months & $2.8 \pm 1.0$ & $1.1 \pm 0.4^{\mathrm{b}}$ & $8(22.8)$ & $16(45.7)^{\mathrm{b}}$ \\
\hline
\end{tabular}

Data are presented as the mean \pm standard deviation. ${ }^{\mathrm{a}} \mathrm{P}<0.01 \mathrm{vs}$. the prior to treatment group; ${ }^{\mathrm{b}} \mathrm{P}<0.05$ vs. the short-course treatment group.

Table IV. Comparison of ALB content prior to and following treatment between the short- and long-course groups.

\begin{tabular}{|c|c|c|c|c|}
\hline \multirow[b]{2}{*}{ Time point } & \multicolumn{2}{|c|}{ ALB content $(\mathrm{g} / \mathrm{l})$} & \multicolumn{2}{|c|}{ ALB recovered to normal $(\%)$} \\
\hline & $\begin{array}{l}\text { Short-course } \\
\text { treatment group }\end{array}$ & $\begin{array}{l}\text { Long-course } \\
\text { treatment group }\end{array}$ & $\begin{array}{c}\text { Short-course } \\
\text { treatment group }\end{array}$ & $\begin{array}{l}\text { Long-course } \\
\text { treatment group }\end{array}$ \\
\hline Prior to treatment & $20.8 \pm 7.1$ & $20.9 \pm 6.3$ & - & - \\
\hline \multicolumn{5}{|c|}{ Following treatment } \\
\hline 1 month & $27.7 \pm 6.8$ & $26.5 \pm 6.8$ & $5(14.3)$ & $4(11.4)$ \\
\hline 3 months & $28.8 \pm 5.7$ & $28.5 \pm 6.6$ & $10(28.6)$ & $9(25.7)$ \\
\hline 6 months & $32.7 \pm 7.4$ & $31.3 \pm 7.3$ & $13(37.1)$ & $15(42.9)$ \\
\hline 12 months & $35.3 \pm 4.8$ & $35.9 \pm 5.0$ & $17(48.6)$ & $18(51.4)$ \\
\hline 18 months & $32.4 \pm 5.3$ & $37.0 \pm 5.7^{\mathrm{a}}$ & $16(45.7)$ & $21(60.0)^{\mathrm{a}}$ \\
\hline 24 months & $32.2 \pm 4.8$ & $38.6 \pm 5.3^{\mathrm{a}}$ & $12(34.3)$ & $19(54.3)^{\mathrm{a}}$ \\
\hline
\end{tabular}

Data are presented as $\mathrm{n}$, the mean \pm standard deviation. ${ }^{a} \mathrm{P}<0.05$ vs. the short-course treatment group. ALB, albumin.

Table V. Comparison of Scr levels prior to and following treatment between the short- and long-course treatment groups.

\begin{tabular}{lcc}
\hline & \multicolumn{2}{c}{ Scr level $(\mu \mathrm{mol} / \mathrm{l})$} \\
\cline { 2 - 3 } Time point & $\begin{array}{c}\text { Short-course } \\
\text { treatment group }\end{array}$ & $\begin{array}{c}\text { Long-course } \\
\text { treatment group }\end{array}$ \\
\hline Prior to treatment & $94.6 \pm 37.0$ & $93.1 \pm 44.0$ \\
Following treatment & & \\
1 month & $93.6 \pm 32.8$ & $90.6 \pm 43.7$ \\
3 months & $89.0 \pm 40.0$ & $91.3 \pm 38.9$ \\
6 months & $84.6 \pm 32.6$ & $86.4 \pm 35.2$ \\
12 months & $86.9 \pm 41.6$ & $87.5 \pm 38.0$ \\
18 months & $89.5 \pm 32.6$ & $91.7 \pm 35.8$ \\
24 months & $92.0 \pm 25.6$ & $93.3 \pm 24.1$ \\
\hline
\end{tabular}

Data are presented as the mean \pm standard deviation. Scr, serum creatinine.
Table VI. Comparison of blood glucose prior to and following treatment between the short- and long-course groups.

\begin{tabular}{lcc}
\hline & \multicolumn{2}{c}{ Blood glucose (mmol/l) } \\
\cline { 2 - 3 } Time point & $\begin{array}{c}\text { Short-course } \\
\text { treatment group }\end{array}$ & $\begin{array}{c}\text { Long-course } \\
\text { treatment group }\end{array}$ \\
\hline Prior to treatment & $5.2 \pm 0.8$ & $5.3 \pm 1.0$ \\
Following treatment & & \\
1 month & $5.9 \pm 1.1$ & $5.6 \pm 1.0$ \\
3 months & $5.2 \pm 1.5$ & $6.1 \pm 0.9$ \\
6 months & $5.3 \pm 0.4$ & $5.2 \pm 1.0$ \\
12 months & $5.4 \pm 1.1$ & $5.3 \pm 0.8$ \\
18 months & $5.5 \pm 1.3$ & $5.5 \pm 1.0$ \\
24 months & $5.4 \pm 1.1$ & $5.5 \pm 0.8$
\end{tabular}

Data are presented as the mean \pm standard deviation. 
Table VII. Univariate analyses of adverse effects in the short- and long-course groups.

\begin{tabular}{|c|c|c|c|c|}
\hline Parameter & $\begin{array}{l}\text { Group with no } \\
\text { adverse effects }\end{array}$ & $\begin{array}{c}\text { Group with } \\
\text { adverse effects }\end{array}$ & F-value & P-value \\
\hline Age, years & $45.4 \pm 17.1$ & $58.6 \pm 13.5$ & 6.153 & 0.025 \\
\hline ALB at 6 months following treatment, $\mathrm{g} / \mathrm{l}$ & $23.3 \pm 5.6$ & $32.3 \pm 7.5$ & 5.563 & 0.037 \\
\hline ALB at 12 months following treatment, $\mathrm{g} / \mathrm{l}$ & $28.1 \pm 2.9$ & $35.2 \pm 6.7$ & 6.201 & 0.029 \\
\hline Urine protein content at 6 months following treatment, g/day & $2.3 \pm 2.0$ & $4.8 \pm 2.2$ & 4.532 & 0.040 \\
\hline Urine protein content at 12 months following treatment, $\mathrm{g} / \mathrm{day}$ & $1.5 \pm 1.1$ & $5.6 \pm 2.0$ & 5.322 & 0.032 \\
\hline
\end{tabular}

Data are presented as the mean \pm standard deviation. ALB, albumin.

biochemical indices and treatment time of the two groups of patients and the results demonstrated that age, serum ALB and the quantity of protein in urine at 6 and 12 months following treatment may be risk factors for adverse effects (Table VII).

\section{Discussion}

IMN is one of the most common pathologies that trigger adult nephrotic syndromes (1). The majority of patients (50-90\%) manifest nephrotic syndromes, whereas others exhibit non-nephrotic proteinuria (1). In recent years, various antigens, including the M-type phospholipase A2 receptor have been identified as important mechanisms for the pathogenesis of IMN (11-13). The course of IMN varies and according to renal function and degree of proteinuria, IMN is divided into low-risk, moderate-risk and high-risk subtypes (1). Patients with low-risk IMN primarily receive symptomatic and supportive treatments whereas tacrolimus combined with low-dose prednisone is recommended for patients with high-risk factors (7). Tacrolimus is an inhibitor of calcineurin that interferes with calcium-dependent signaling pathways, blocks transcription in early $\mathrm{T}$ cell lymphocytes and inhibits the activation and proliferation of $\mathrm{T}$ cells (7). In addition, tacrolimus serves an immunosuppressive role by inhibiting $\mathrm{T}$ cell-derived growth factors to inhibit B cell growth and antibody formation (7). For this reason, the drug has drawn increasing attention for its use in IMN treatment. A previous meta-analysis including a total of 1,762 participants revealed that therapy with immunosuppressive agents significantly increased the rate of remission, reduced the risk of all-cause mortality and end-stage renal failure, and that treatment with tacrolimus in combination with low-dose prednisone significantly reduced proteinuria (14). A number of clinical studies have also demonstrated that the efficacy of tacrolimus treatment with low-dose prednisone for IMN is superior to that of conventional regimens and that this treatment significantly improves the clinical remission rate of patients with IMN (15-18). However, recurrence rate is high following the withdrawal of tacrolimus (19). A previous study has demonstrated that the time to remission and the duration of treatment by tacrolimus are factors associated with recurrence (20). Reducing the recurrence rate is associated with the patient prognosis; therefore, the present study conducted a randomized controlled experiment to assess the efficacy and safety of patients with IMN and nephrotic syndromes, receiving treatment for 12 and 24 months. The results demonstrated that low-concentration tacrolimus in the long-course group, alleviated the condition of the disease with a low recurrence rate (19). However, due to the relatively high prices of tacrolimus and an increased risk of side effects following long-term use (21), the appropriate duration of treatment maintenance remains inconclusive.

To the best of our knowledge, the present study assessed whether there were differences in efficacy and safety between short- and long-course tacrolimus treatment for the first time. The results demonstrated that short- and long-course treatment significantly alleviated IMN; however, the disease recurred in 8 patients in the short-course group and 4 patients in the long-course group following drug withdrawal. Levels of urine proteins in the long-course group were significantly reduced compared with the short-course group at 18 and 24 months following treatment $(\mathrm{P}<0.05)$.

A previous study has demonstrated that the primary adverse effects of tacrolimus are liver and kidney toxicity, elevated blood glucose, gastrointestinal reactions, respiratory infections and rare epilepsy (22). Another previous study revealed that the incidence rate of adverse effects is relatively lower following treatment with corticosteroids combined with tacrolimus for IMN (23). In the present study, there were 11 patients with adverse effects, of whom 6 patients were excluded within 2-10 months due to serious adverse effects. The main adverse effects were elevated blood glucose and respiratory infections; however, this may have been partly caused by the combination of prednisone, as they are common side effects (1). In future studies, it may be necessary to evaluate the efficiency and safety of tacrolimus monotherapy and that combined with prednisone for the treatment of IMN. In the present study, serious adverse effects included respiratory diseases, in which pneumonia was the most serious, causing 3 patients to succumb, suggesting that preventive measures need to be strengthened for serious adverse effects of tacrolimus, particularly for severe infections. These effects should be closely monitored during medication and the self-protection of patients, such as wearing a mask to avoid infection, following discharge should be strengthened.

The current study demonstrated that long-course tacrolimus combined with low-dose hormone may effectively treat IMN. Compared with short-course therapy, long-course therapy has a relatively higher remission rate and lower recurrence rate $(11.4 \%)$. The main adverse effects of the patients were elevated blood glucose and respiratory infections. The former may return to normal following diet control or drug treatment; 
however the latter may have more serious implications. Age, serum ALB and the quantity of urinary proteins may be risk factors for adverse effects. However, there was no significant difference in the incidence rate of adverse effects (13.1 vs. $15.8 \%$ ) between the short- and the long-course treatment group. The results of the present study indicate that long-course tacrolimus combined with low-dose hormone is a preferable therapy for the treatment of idiopathic membranous nephropathy compared with short-course treatment. However, the efficacy and safety of prolonged tacrolimus treatment combined with corticosteroids for IMN should be further explored in future studies with a larger sample size and a longer follow-up period.

\section{Acknowledgements}

Not applicable.

\section{Funding}

No funding was received.

\section{Availability of data and materials}

All data generated or analyzed during this study are included in this published article.

\section{Authors' contributions}

JD designed the present study and prepared the manuscript; QQ and HZ collected all data; MY and ML analyzed the data; YPJ and YZ interpreted the data; YZ collected funding. All authors read and approved the final manuscript.

\section{Ethics approval and consent to participate}

The present study was approved by the Ethics Committee of the First People's Hospital of Changzhou. Written, informed consent was obtained from all patients prior to their inclusion within the study.

\section{Consent for publication}

Patients provided written, informed consent for the publication of their data.

\section{Competing interests}

The authors declare that they have no competing interests.

\section{References}

1. Massry SG and Glassock RJ: Massry \& Glassock's textbook of nephrology. Lippincott Williams \& Wilkins, Philadelphia, PA, pp701-713, 2001.

2. Ronco P and Debiec H: Pathogenesis of membranous nephropathy: Recent advances and future challenges. Nat Rev Nephrol 8 : 203-213, 2012.

3. Waldman M and Austin HA III: Treatment of idiopathic membranous nephropathy. J Am Soc Nephrol 23: 1617-1630, 2012.

4. Kidney Disease: Improving Global Outcomes (KDIGO): KDIGO Clinical Practice Guideline for Glomerulonephritis. Kidney Int Suppl 2: 139-274, 2012.
5. Perna A, Schieppati A, Zamora J, Giuliano GA, Braun N and Remuzzi G: Immunosuppressive treatment for idiopathic membranous nephropathy: A systematic review. Am J Kidney Dis 44: 385-401, 2004.

6. Schieppati A, Perna A, Zamora J, Giuliano GA, Braun N and Remuzzi G: Immunosuppressive treatment for idiopathic membranous nephropathy in adults with nephrotic syndrome. Cochrane Database Syst Rev 18: CD004293, 2004.

7. Scott LJ, McKeage K, Keam SJ and Plosker GL: Tacrolimus: A further update of its use in the management of organ transplantation. Drugs 63: 1247-1297, 2003.

8. Ramachandran R, Hn HK, Kumar V, Nada R, Yadav AK, Goyal A, Kumar V, Rathi M, Jha V, Gupta KL, et al: Tacrolimus combined with corticosteroids versus Modified Ponticelli regimen in treatment of idiopathic membranous nephropathy: Randomized control trial. Nephrology (Carlton) 21: 139-146, 2016.

9. Ramachandran R, Kumar V, Nada R, Kohli HS, Jha V and Gupta KL: Tacrolimus with corticosteroids is inferior to modified Ponticelli regimen in the management of primary membranous nephropathy: Results at 2 years of randomization. Nephrol Dial Transplant 31 (Suppl 1): i77, 2016.

10. Xu J, Zhang W, Xu Y, Shen P, Ren H, Wang W, Li X, Pan X and Chen N: Tacrolimus combined with corticosteroids in idiopathic membranous nephropathy: A randomized, prospective, controlled trial. Contrib Nephrol 181: 152-162, 2013.

11. Debiec H, Guigonis V, Mougenot B, Decobert F, Haymann JP, Bensman A, Deschênes G and Ronco PM: Antenatal membranous glomerulonephritis due to anti-neutral endopeptidase antibodies. N Engl J Med 346: 2053-2060, 2002.

12. Qin W, Beck LH Jr, Zeng C, Chen Z, Li S, Zuo K, Salant DJ and Liu Z: Anti-phospholipase A2 receptor antibody in membranous nephropathy. J Am Soc Nephrol 22: 1137-1143, 2011.

13. Prunotto M, Carnevali ML, Candiano G, Murtas C, Bruschi M, Corradini E, Trivelli A, Magnasco A, Petretto A, Santucci L, et al: Autoimmunity in membranous nephropathy targets aldose reductase and SOD2. J Am Soc Nephrol 21: 507-519, 2010.

14. Chen Y, Schieppati A, Cai G, Chen X, Zamora J, Giuliano GA, Braun $\mathrm{N}$ and Perna A: Immunosuppression for membranous nephropathy: A systematic review and meta-analysis of 36 clinical trials. Clin J Am Soc Nephrol 8: 787-796, 2013.

15. Chen M, Li H, Li XY, Lu FM, Ni ZH, Xu FF, Li XW, Chen JH and Wang HY; Chinese Nephropathy Membranous Study Group: Tacrolimus combined with corticosteroids in treatment of nephrotic idiopathic membranous nephropathy: A multicenter randomized controlled trial. Am J Med Sci 339: 233-238, 2010.

16. Qi JC, Liu PG, Wang C, Zheng AD and Wan Z: Tacrolimus protects vascular endothelial cells from injuries caused by Ox-LDL by regulating endoplasmic reticulum stress. Eur Rev Med Pharmacol Sci 21: 3966-3973, 2017.

17. Santosh T, Liu H and Liu B: Effect of tacrolimus in idiopathic membranous nephropathy: A meta-analysis. Chin Med J (Engl) 127: 2693-2699, 2014.

18. Ballarin J, Poveda R, Ara J, Pérez L, Calero F, Grinyó JM and Romero R: Treatment of idiopathic membranous nephropathy with the combination of steroids, tacrolimus and mycophenolate mofetil: Results of a pilot study. Nephrol Dial Transplant 22: 3196-3201, 2007.

19. Arikan H, Koc M, Cakalagaoglu F, Eren Z, Segal MS, Tuglular S, Ozener $C$ and Akoglu E: Tacrolimus rescue therapy in resistant or relapsing cases of primary glomerulonephritis. J Nephrol 21: 713-721, 2008.

20. Caro J, Gutiérrez-Solís E, Rojas-Rivera J, Agraz I, Ramos N, Rabasco C, Espinosa M, Valera A, Martín M, Frutos MÁ, et al: Predictors of response and relapse in patients with idiopathic membranous nephropathy treated with tacrolimus. Nephrol Dial Transplant 30: 467-474, 2015.

21. Yuan H, Liu N, Sun GD, Jia Y, Luo P and Miao LN: Effect of prolonged tacrolimus treatment in idiopathic membranous nephropathy with nephrotic syndrome. Pharmacology 91: 259-266, 2013.

22. Yağmurdur MC, Sevmis S, Emiroğlu R, Moray G, Bilgin N and Haberal M: Tacrolimus conversion in kidney transplant recipients: Analysis of 107 patients. Transplant Proc 36: 144-147, 2004.

23. He L, Peng Y, Liu H, Liu Y, Yuan S, Liu F, Yang D, Liu H, Chen X, Shao J and Fu M: Treatment of idiopathic membranous nephropathy with combination of low-dose tacrolimus and corticosteroids. J Nephrol 26: 564-571, 2013. 